\title{
Economic and Organizational Transition towards Product/Service Systems: The Case of French SMEs
}

\author{
Xavier Boucher \\ Ecole Nationale Supérieure des Mines de Saint Etienne, Fayol-EMSE \\ F-42023 Saint Etienne, France \\ Boucheraemse.fr
}

\begin{abstract}
The French ANR Project ServINNOV intends to analyze the transition of industrial SMEs towards the integration of service activities and the production of PSS Systems. Based on the first results of a qualitative analysis of a set of 8 case studies, the paper discusses key factors influencing such organizational transitions.
\end{abstract}

Keywords: Product-Service Systems, Servicization, Transition of business model.

\section{Introduction}

This paper presents a research approach developed by the French ANR project ServINNOV "Sustainable Industrial Innovation via Servicization", and some first results. This project studied the economic and organizational transition of industrial Small and Medium Enterprises (SMEs) towards a service economy, or more precisely towards a functional economy [1]. This transition to the progressive integration of service activities in industrial firms together with their more traditional manufacturing oriented activities induces [3] a profound makeover of enterprise models: a transformation of both business and organizational models, called servicization [4]. Servicization deals with the development of integrated product/service offers, also called PSS (Product Service Systems). Currently, such new enterprise models are emerging within the international economy.

Integrated product/service offers brings new research questions for collaboration: (i) internal collaboration problems emerges at along the frontier among manufacturing-oriented and service-oriented business processes ; (ii) external collaboration is also strongly necessary, because such integrated offers require at their heart, value creation collaborative firm networks. As a first stage of research in this new innovative domain, our paper will only focus on better understanding product/service coupling mechanisms within the context of SMEs, with the following objectives: (1) the identification of various coupling modes between product oriented and service oriented business processes, and (2) the identification of transition drivers 
and influence factors to be considered by managers when building integrated product/service offers. Section 2 introduces the notion of product/service coupling with a state of the art which underlines the variety of potential coupling modes. Section 3 explains the organization of the research program and presents several case studies used to generate the results discussed in this paper. Section 4 presents some first results concerning distinct modes of product/service coupling, then influencing factors considered by SME managers when developing product/service market offers.

\section{State of the Art: Variety of Coupling Modes between Manufacturing-oriented and Service-oriented Business Processes}

This research work attempts to better understand the dependency between productoriented and service-oriented business processes within a single enterprise. That means that, as a hypothesis, our work centers on companies which intend to develop internally both 'service-oriented' and 'manufacturing-oriented' activities. Such organizational coupling brings new questions on collaboration: internal cooperation between various entities of a company, and external alliances among companies. The study, strives to identify the mutual influences among material production processes and immaterial service offers, along the path of development and innovation in a company.

Academic literature provides various typologies which can be used as basis to manage such complexity. Balin [5] provides a large state of the art on typologies which directly concentrate on the service concept. The author distinguishes 3 main orientations : (1) economic oriented typologies (classification criteria are linked to the nature of the economic activity); ( 2) marketing oriented typologies, where the classification criteria concern marketing features of the service offers, customer implication level, or delivery modes; and, finally, (3) typologies directly based on the client implication, where criteria are linked to the volume and variety of the market as well as customization level which are eventually used jointly with other criteria linked to the type of service production process.

Although they are mainly centered on services, such typologies cannot completely ignore the product: either because a material product is the concrete object of the service (for instance maintenance service), or because the material product is directly one of the components of the offer (for instance a service offering the access to use specific equipment). For example, the service typology provided by Fitzimmons [6] uses a criteria 'Process object' by distinguishing 'Material oriented', 'Information oriented' and 'Person oriented' services separately. Giard has elaborated an interesting synthesis [7] which proposed a classification which integrates the link among products and services, both of final consumer oriented services (B to $C$ ) and business oriented services (B to B). The main classification criteria is the object of the service offer, consider as a 'Product use offer', 'Information use offer' or a 'Resource state transformation'. 
Beyond service classifications, whose aim is to manage the complexity of these notions, several academic publications are more directly interested in the process dependency among product manufacturing and service production. In the field of industrial strategy, the framework of Johansson \& Ohlager [8] analyses the pertinence and consistency of various coupling alternatives. Their framework is based on a criterion of demand level for both the product and service activities, then on a criterion for the process control level (on one side for the manufacturing processes and on the other side for the processes needed to produce the services).

Complementary to such a strategic vision, other authors only focus on classifying the nature of the PSS offer. Hockerts [9], Manzini [8], Tukker [10] or more recently Baines [1] have progressively converged towards a widely accepted typology :

- Product Oriented PSS: the product is sent in an ordinary fashion, but the sales contract includes services deployed along the product life-cycle.

- Use oriented PSS: the provider only contracts an access or a utilization of a product, without product purchase for the customer.

- Result oriented PSS: Independently of any pre-defined product, the provider guaranties to answer specific customer needs, with a contracted engagement on the final result/performance.

\section{Research Approach}

\subsection{Overview on the Research Program}

In a regional context of industrial SMEs, the objective of these research efforts is to identify and understand various product/service coupling forms. This paper only delineates a first step of the research, anterior to the scientific formalisation, which consists in structuring consistent information collected to be deployed in industrial companies, and to extract the first, non-formalized, comprehension of the product/service coupling mechanisms under study.

The research approach is standard, and based on three separate but complementary objectives:

1. Analysis of the academic literature. The scientific literature is analyzed following two tracks: first the PSS systems, to identify coupling parameters between service and manufacturing oriented activities which are induced by the PSS offer; second the Service Oriented Enterprise (SOE), to identify strategic and organisational characteristics of such SMEs. The objective is to analyze the correspondence among the PSS system characteristics and the features of the associated productive system.

2. Diagnosis tool building. Two tools have been built, to be used as a support later diagnostics. First, an interview guide (Semi-structured information collection), structuring the information to be gathered by interviewing top managers of SMEs. And second, a modelling referential, which is capable of modelling structurally, enterprise practices used to manage client/customer relationships. 
3. Analysis of cases studies. As we will further develop below, 8 case studies of regional SMEs made from various interviews with general and industrial managers are used to try and analyse the variety of coupling modes among product and services as well as the advances of the companies towards this integration.

\subsection{Analysis of Case Studies}

The qualitative study is based on a collection of 8 case studies (table 1). The objective is to follow a qualitative analysis approach adapted to a reduced set of case studies. The nearby SMEs have been selected via the fact that they incorporate both internal manufacturing activities and service-oriented initiatives. However, one additional criterion must be considered: all the case studies are in the field of $\mathrm{B}$ to $\mathrm{B}$. This ensures higher coherence of the analysis, since B to B or B to C present significant differences as to servicization. In table 1, some descriptive features are presented.

In qualitative research, case studies are used to understand and model emerging phenomenon, confront hypotheses with reality, and provide a clearer and better comprehension of the reality under study [12]. These case studies have been constituted following a so-called 'narrative' approach: during each interview, top managers are asked to make explicit the company history highlighting on the key moments of change, which underline significant strategic decisions. This narrative approach can make explicit firm transformational processes. It is based on a rather detailed account of a change process, through organization description, analysis of activity or complementary dialogs. In the current work, the interview directly concerned top managers of SMEs to be able to address the strategic trajectory of the company.

Table 1. Eight Case Studies

\begin{tabular}{|c|c|c|c|}
\hline Firm & Business sector & Size & Contact \\
\hline $\mathrm{A}$ & $\begin{array}{c}\text { Mechanics industry } \\
\text { Design/Manufacturing }\end{array}$ & 10 & Top Manager \\
\hline $\mathrm{B}$ & $\begin{array}{c}\text { Medical Products } \\
\text { Design/Manufacturing/Sales }\end{array}$ & 100 & Top Manager \\
\hline $\mathrm{C}$ & $\begin{array}{c}\text { Metal spring } \\
\text { Supply Chains Subcontractor } \\
\text { Design/Manufacturing }\end{array}$ & 30 & Top Manager \\
\hline $\mathrm{D}$ & $\begin{array}{c}\text { Surface processing. } \\
\text { Service offers. Design and manufacturing of } \\
\text { industrial processes }\end{array}$ & 1200 & $\begin{array}{c}\text { R\&D business sector } \\
\text { manager }\end{array}$ \\
\hline $\mathrm{E}$ & $\begin{array}{c}\text { Production of machining centers. } \\
\text { Design/Manufacturing/After Sales } \\
\text { Integrator of subsystems. }\end{array}$ & 150 & Top Manager \\
\hline $\mathrm{F}$ & $\begin{array}{c}\text { Tooling Industry. } \\
\text { Design/Manufacturing/Tool sharpening } \\
\text { Subcontractor }\end{array}$ & 70 & Top Manager \\
\hline $\mathrm{H}$ & $\begin{array}{c}\text { Industrial machines and processes } \\
\text { Design/Production/industrialization of new } \\
\text { processes }\end{array}$ & 60 & Industrial Manager \\
\hline
\end{tabular}


Our objective was to try and understand the mechanisms of change driving the progressive integration of services in manufacturing companies. Through the company story, it was necessary to make explicit the origin of the evolution on the way to services, progressive transformation of its industrial strategy, and renovation of the organization modes as well as collective competencies. The semi-structured interview guide consisted mainly of open questions. Thus, giving the managers an the opportunity of a spontaneous expression, before going deeper on some key points. Among the various chapters of information collected, we insisted notably on productservice offers, the internal development of a service culture, transformation of customer relation ship, as well as the innovations on production modes and their impacts on internal proficiency.

\section{$4 \quad$ First Synthesis of Results}

\subsection{Variety of Product/Service Coupling Modes}

All the case studies concern SMEs with an industrial history and culture, oriented on design and/or manufacturing of products. In all the companies, the notion of services has emerged progressively, always with a strong link to production activities. The study shows that the managers have very diverse perceptions and comprehensions of the notion of service. We identified 3 distinct visions of the integration of services in industrial activities, illustrated by some examples in table 2 .

Table 2. Diversity of the integration of services within industrial activities

\begin{tabular}{|c|c|c|c|c|}
\hline & Firm A & Firm H & Firm F & Firm G \\
\hline $\begin{array}{l}\text { Providing } \\
\text { quality of service }\end{array}$ & $\begin{array}{l}\text { Client orientation } \\
\& \text { integrated offer }\end{array}$ & $\begin{array}{l}\text { Development and } \\
\text { Management of } \\
\text { Quality of Service }\end{array}$ & $\begin{array}{l}\text { Client orientation } \\
\& \text { Quality of } \\
\text { service }\end{array}$ & $\begin{array}{l}\text { Client orientation } \\
\& \text { integrated offer }\end{array}$ \\
\hline $\begin{array}{l}\text { Offering } \\
\text { differentiated } \\
\text { services }\end{array}$ & I & $\begin{array}{l}\text { Specific business } \\
\text { sector } \\
\text { 'customized } \\
\text { products' }\end{array}$ & Tool sharpening & $\begin{array}{l}\text { Sales of technical } \\
\text { Competencies }\end{array}$ \\
\hline $\begin{array}{l}\text { Developing PSS } \\
\text { offers }\end{array}$ & $\begin{array}{l}\text { Transition } \\
\text { towards a global } \\
\text { capacity offer }\end{array}$ & I & $\begin{array}{l}\text { Servicization } \\
\text { model under } \\
\text { study }\end{array}$ & / \\
\hline
\end{tabular}

- $\quad$ Providing quality of service associated to the product. Historically, all the SMEs analyzed have first tried to increase systematically the "quality of services" in producing and delivering their industrial products. The orientation towards customers turns out to be re-enforced, new service-oriented competences emerge together with a new vision of the product offer.

- Offering differentiated services. Complementary to product sells, new serviceoriented business area is developed. These first service offers are directly linked to the product life cycle. Specific service oriented competences have to be 
developed. The manufacturing processes and service production processes remain separated, only linked by the product life-cycle and the competencies required.

- Developing PSS offers. Here, the selling products and services are both integrated in a unique economic and contractual relationship with the customer. The economic model is profoundly transformed. Depending on the context, the various forms of PSS underlined in section 2.1can appear.

Depending on the context of each case study, the product-service coupling strategies remain very specific to each form. The progressive development of services in industrial SMEs appears to depend on several influencing factors (see section 4.4). The study emphasized both (i) a necessity of internal coherence among these various influencing factors, shared by all the companies, but also (ii) a clear differentiation of strategic positioning and decisions for each particular case. This induces that the 3 visions of service integration mentioned in table 2 could not be assigned to generic types of SMEs; however there is certainly genericity in the influencing factors to consider and decision process to ensure internal coherence among these factors.

The various case studies also put forth that this transition towards services is a progressive process over time. The development of services appears as systematically linked to intentional changes of vision in the company history. These changing points also induce a transformation in internal proficiencies, which requires integration and learning periods. Afterwards, such transitions can generate new opportunities.

However, in spite of this temporal factor, the 3 visions of table 2 can not be considered as progressive maturity levels towards services. For all the case studies, Providing quality of service associated to the product was a shared starting point of the strategic progress. However the transition towards PSS does not require offering differentiated services previously. Furthermore, several of these 3 visions can co-exist in a same SME (in various business areas).

The interviews have underlined 3 main types of managerial drivers for the transition towards product/service coupling: (i) re-enforcement of firm core competencies, (ii) long term vision of maintaining both industrial and service capabilities and (iii) need for innovation. Due to a lack of available place, they can not be discussed in this paper, but the reader can refer to [14].

\subsection{Influence Factors to Build Product/Service Offers}

\subsubsection{Complexity}

Three distinct forms of complexity, influencing the strategic choices of SMES managers can be underlined:

- Product technological complexity: the increase of product complexity is linked to need of differentiating product added-value. Higher product complexity can generate higher potential of product-associated services. The integration of multiple know-how and competences in complex products offers new opportunities for offers of specific services.

- The client/provider relationship complexity: in $\mathrm{B}$ to $\mathrm{B}$ relationships, there is a transformation of the client/provider relation towards a demand of providing 
complex integrated functions, with a significant adaptation to the specific requirements of each customer. A large part of the complexity of project management of integrated product/services is transferred from the client in the direction of the provider.

- Usage complexity: linked to the other forms of complexity, the complexity of B to $\mathrm{B}$ product life-cycle management also increases. Depending on the degree of complexity, internal skills of the clients and other life-cycle actors, as well as on the competencies of the provider, the product-life cycle can generate service offers opportunities.

As influencing factors, which correspond to the needs of service offers associated with a product and its life-cycle, these 3 forms of complexity should be considered by the managers when determining their broad product-service market offers.

\subsubsection{Internal Competences}

Several mechanisms of mutual adjustment appear, among available competencies on one side and services offers on the other one. They underline a dynamic process of co-evolution among internal competencies and offers of product-service systems.

- All the SMEs' managers underline the need to develop a collective firm competency, oriented on 'service' culture. This includes: capability to better perceive the customer needs and ability to answer, even proactively, to the variety of the demand, beyond the direct technical need. This collective serviceoriented culture induces a transformation of individual competencies as well as re-enforced integration mechanisms among Marketing, Innovation and Production.

- The development of a service offer remains under the constraint of the competencies required to ensure this service. This constraint is both qualitative (which ones are necessary?) and quantitative (a full network required to cover the territory). This appears as a strong constraint for SMES, however partnership strategies afford potential organizational answers (see the section that follows).

- The internal integration of new competencies also opens innovative opportunities of service offers. A two-directional interaction appears between integrating new competencies and innovation in services. In several cases, the internal acquisition of new differentiating competencies required for a first service offer, generates afterwards additional opportunities of service innovations.

- Additionally, SMEs managers put forth that the development of product/service offers leads to the emergence of a new strategic collective competence. In fact, service deployment is based on a close proximity to the customers. As a consequence, service production becomes crucial in customer relationships. Thus, it can become a key source of innovation. Such new strategic competence takes distinct forms depending on which case study considered.

A more systematic analysis of the link between competencies and service offers would be interesting to better understand this dynamic process of co-evolution. 


\subsubsection{Partnership Strategies}

Of course, strategies of external alliances have been developed for long time by most SMES. However, in the context of emergence of service/product coupling, partnerships become a deliberate managing lever, notably (i) because the complexity increase induce the need of integrating multiple know-how and (ii) because ensuring service of a large territory requires a full service network. The service infrastructure is often built on partnership, so as to share the investment...and the risks. Such partnerships induce strong added-value sharing risks. Currently the approaches for servicization risk management appear to be unique to each context. There is a clear need to better adapt risk managing solutions.

\subsubsection{Investment and Innovation Policies}

The study underlines that investment and innovation policies strongly influence the development of product/service coupling. For the 8 case studies, innovation of service systematically responds to a need of new sources of value creation. As mentioned before, service production can be transformed into a strong driver of innovation. However, most of the time, SMEs are confronted with an intense need for both the human and technical investment required for service production. Internal financing limits as well as French difficulties to get access correctly or easily to institutional or bank funding support can become very limiting (Case A, D, F, G).

\section{Conclusion}

Only partial results of the case studies developed for the SPOS project have been presented within the limit of this paper. The various forms of product-service coupling, as well as crucial factors which influence managers when determining their strategies of integrated product-service offers were focused upon. Four key influencing factors have been emphasized: all of them are correspond to internal managerial aspects. Additionally external factors of innovation strategy have also to be considered as changes in PSS offers, customer behaviors, technological progress changes,.... Such factors will be developed in further publications. Beyond the academic knowledge generated by the study, a future perspective will be to build diagnosis methods and tools to help managers to manage the economic and organizational transition towards product-service coupling.

Acknowledgement. the authors wish to thank Chris Yukna for his help in proofreading.

\section{References}

1. DuTertre, C.: Modèle industriel "et" modèle serviciel de performance. In: XVIIth International Conference of RESER, Tampere, Finlande, Septembre 13-15 (2007)

2. Baines, T.S., Lightfoot, H.W., Evans, S., et al.: State-of-the-art in product-service systems. In: Proceedings of the Institution of Mechanical Engineers, Part B: Journal of Engineering Manufacture, pp. 1543-1552 (2007) 
3. Baines, T.S., Lightfoot, H.W.: Towards an Operations Strategy for the infusion of ProductCentric Services into Manufacturing, into Service Systems Implementation. In: Demirkan, H., Spohrer, J.C., Krishna, V. (eds.) Springer (2011)

4. Balin, S.: Amélioration de processus de production de services par la simulation. $\mathrm{PhD}$ thesis, University Paris Dauphine (2007)

5. Fitzsimmons, M.J.: Service Management. McGraw Hill, New York (2004)

6. Giard, V.: Ingénierie de Services. Economica, Paris (2005)

7. Johansson, P., Olhager, J.: Linking product-process matrices for manufacturing and industrial service operations. Int. J. Production Economics 104, 615-624 (2006)

8. Manzini, E., Vezzoli, C.: A strategic desaign approach to develop sustainable product service systems: examples taken from the 'environmentally friendly innovation' Italian prize. Journal of Cleaner Production 11, 852-857 (2003)

9. Hockerts, K.: Eco-Efficient Service Innovation: Increasing Business-Ecological efficiency of Products and Services. In: Charter, M. (ed.) Greener Marketing: A Global Perspective on Greener Marketing Practice, pp. 95-108. Gereenleaf Pub., Sheffield (1999)

10. Tukker, A., Van Halen, C.: Innovation Scan for Product Service Systems; A manual for the development of new product-service systems for companies and intermediaries for the SME sector. TNO, PriceWaterhouseCoopers, Delft/Utrecht (2003)

11. Mucchielli, A.: Les méthodes qualitatives. Presses Universitaires de France, Paris (1991) (Que sais-je 3, 2591)

12. Weick, K.E.: Sensemaking in Organizations. Sage, Thousand Oaks (1995) 